
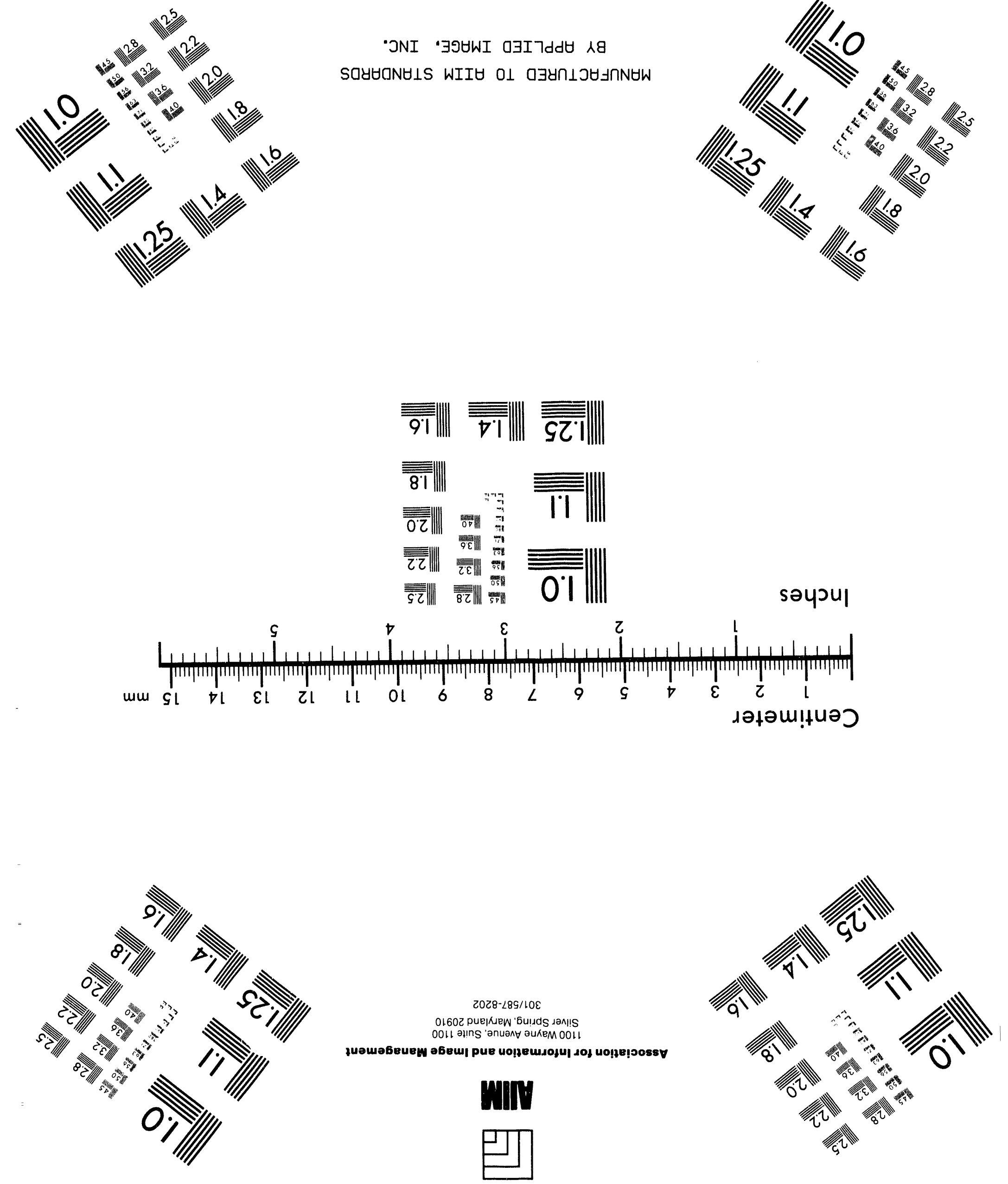

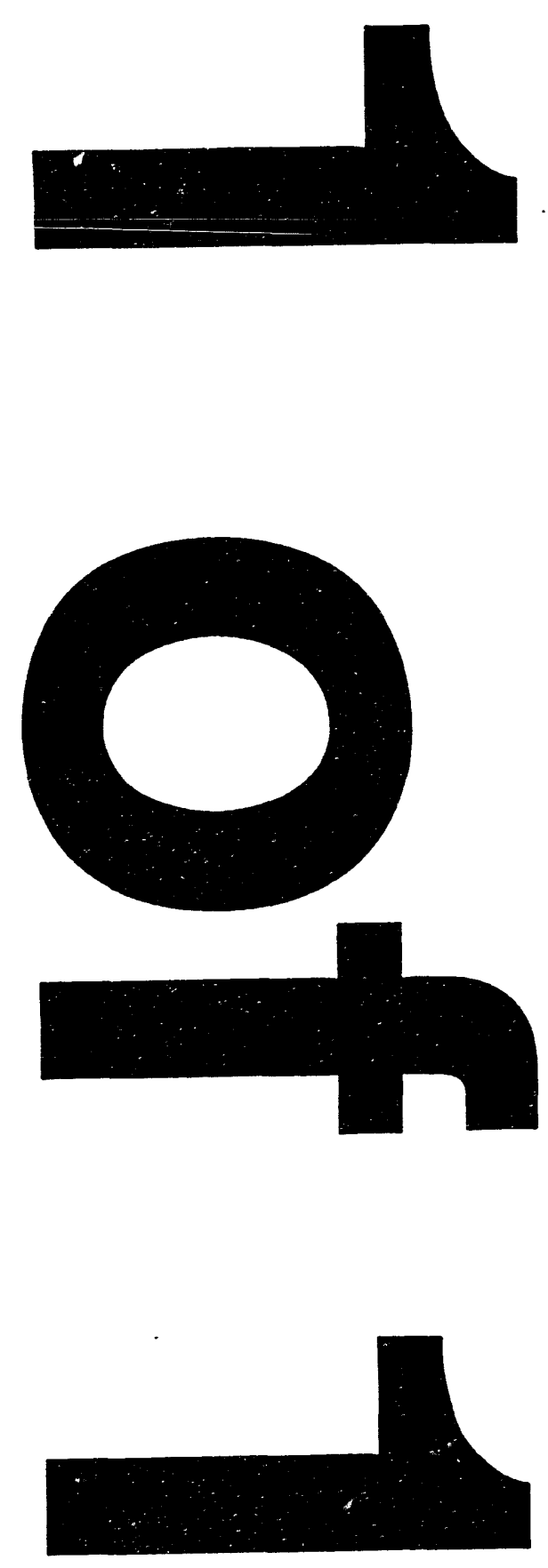


\title{
1993 NORTHERN GOSHAWK INVENTORY ON PORTIUNS OF LOS ALAMOS NATIONAL LABORATORY, LOS ALAMOS, NM
}

\author{
Final Report for Subcontract $9-X-13-590 E E-1$ \\ by \\ David T. Sinton and Patricia L. Kennedy \\ Department of Fisheries and Wildife Biology \\ Colorado State University \\ Fort Collins, CO 80523
}

submitted to:

\author{
Environmental Management-8 \\ Los Alamos National Laboratory \\ Los Alamos, NM
}

\section{DISCLAIMER}

\begin{abstract}
This report was prepared as an account of work sponsored by an agency of the United States Government. Neither the United States Government nor any agency thereof, nor any of their employees, makes any warranty, express or implied, or assumes any legal liability or responsibility for the accuracy, completeness, or usefulness of any information, apparatus, product, or process disclosed, or represents that its use would not infringe privately owned rights. Reference herein to any specific commercial product, process, or service by trade name, trademark, manufacturer, or otherwise does not necessarily constitute or imply its endorsement, recommendation, or favoring by the United States Government or any agency thereof. The views and opinions of authors expressed herein do not necessarily state or reflect those of the United States Government or any agency thereof.
\end{abstract}




\section{INTRODUCTION}

Northern goshawks (Accipiter gentilis) (hereafter referred to as goshawk) is a large forest dwelling hawk. They are the largest species of the Accipiter genus which also includes sharp-shinned hawks (A. striatus) and the Cooper's hawk (A. cooperii). The goshawk is holarctic in distribution and nests in coniferous, deciduous, and mixed species forests. In the southwest they primarily nest in ponderosa pine (Pinus ponderosa), mixed species, and spruce-fir forests (Reynolds et al 1992).

Goshawks may be declining in population and reproduction in the southwestern United States (Reynoids et al 1992). In 1982 the USDA-Forest Service listed the goshawk as a "sensitive species" (USDA Forest Service 1991) and in 1992 the U.S. Fish and Wildlife Service listed the goshawk as a "Category 2 species" in accordance with the Endangered Spgcies Act. Reasons for the possible decline in goshawk populations include timber harvesting resulting in the loss of nesting habitat, toxic chemicals, and the effects of drought, fire, and disease (Reynolds et al 1992). Thus, there is a need to determine their population status and assess impacts of management activities in potential goshawk habitat.

Inventory for the goshawk was conducted on 2,254 ha of Los Alamos National Laboratory (LANL) to determine the presence of nesting goshawks on LANL lands. This information can be incorporated into LANL's environmental management program. The inventory was conducted by Colorado State University personnel from May 12 to July 30,1993 . This report summarizes the results of this inventory. 


\section{METHODS}

The area to be inventoried for goshawks was determined by Environmental Management-8 (EM-8), Los Alamos National Laboratory (LANL)(Map 1). Most of this area was inside the perimeter of the cleared area. For that reason and to comply with EM-8's health and safety procedures, an escort was provided by EM-8 to accompany the observer (DTS) during inventory.

Inventory was conducted from May 12 to July 30, 1993. This period coincides with the goshawk incubation stage, the nestling stage, and the fledglingdependency stage of the goshawk nesting season in the Jemez Mountains (Kennedy 1991). The inventory method was based on the recommended approach detailed in Kennedy and Stahlecker (1993). Because of the steep terrain, inventory routes were conducted along canyon edges and in the bottom of all drainages and side drainages (Map 1). The distance between calling stations was $150 \mathrm{~m}$ (during the incubation stage) and $200 \mathrm{~m}$ (during early nestling to fledgling-dependency stages). This represents a deviation to the Kennedy and Stahlecker method which recommends a 300-m spacing. Since the incubation stage was not included in the Kennedy and Stahlecker experiment and since raptors are known to be less responsive to broadcast vocalizations during incubation (Rosenfield et al 1988, Fuller and Mosher 1981), a closer spacing between stations was implemented during the incubation stage. Because straight transect lines staggered by $130 \mathrm{~m}$ (as recommended in Kennedy and Stahlecker) was not used, the observer reduced the spacing from $300 \mathrm{~m}$ to $200 \mathrm{~m}$ to insure total coverage during brood rearing. Inter-station distances were measured by pacing. 
The broadcast surveys started as early as 07:58 and ended as late as 18:00. A modified Sony Sport Walkman (Model \# Wm-A53) and a modified Realistic Musical Powerhorn (Cat. \# 32-2030A) were used to play and amplify conspecific calls of the goshawk. The goshawk alarm call was used throughout the inventory and tapes were made from commercial recordings o11 compact disc. Recordings of the adult goshawk wail and the juvenile goshawk begging call were not used during the fledgling-dependency period as recommended by Kennedy and Stahlecker because the quality and volume of our recordings of these vocalizations were not suitable for inventory. All raptors detected [excluding turkey vultures (Cathartes aura)] during the survey were recorded on field data forms (Figure 1) and included the species, age, sex, detection type, and direction of the detection. All detections were also marked on maps accompanying each field data form.

Any vocal or aggressive response from an accipiter to the taped calls (including Cooper's hawks and sharp-shinned hawks) would have led to an intensive nest search (Reynolds 1982) in the response area. The search area would cover approximately $2,500 \mathrm{~m}^{2}$ (radius $=800 \mathrm{~m}$ ) and would vary in shape according to terrain and vegetation. Each tree in the immediate area would be scanned using binoculars for an active nest until the nest is located. The observer would also search for the plucked remains of prey, feces, molted feathers, and inactive stick nests. If no nest was found, additional calling would have been conducted to gain more information about the possible nest location. or any additional reason for the response. 


\section{RESULTS}

A total of 43.9 hours were spent inventorying 304 stations on 2,254 ha (Table 1). This includes time spent during breaks, lunch stops, and waiting out rain, hail, and lightning storms and does not include administrative time or time spent accessing the area. On July 30 , an area was re-inventoried because of a sighting of an unidentified accipiter on May 21. The unidentified immature accipiter (either a goshawk or a Cooper's hawk) was observed in a side drainage to Cañon de Valle (Table 2 and Map 2). It was not observed again during the repeat inventory. Inside the inventory area no additional potential goshawk responses were detected. In Two-Mile Canyon a Cooper's hawk was seen flying overhead at a great distance (Table 2 and Map 2) and a red-tailed hawk (Buteo jamacensis) nest with three nestlirigs was found. Red-tailed hawks were seen on three other occasions. A great horned owl (Bubo virginesis) was seen on one occasion and a vacant great horned owl nest was located in Pajarito Canyon.

The results of this survey can be interpreted in several ways: 1) no goshawk territories occur in the inventoried area; 2 ) goshawk territory(ies) exist but have failed prior to the survey and thus were not detected; or 3) territory(ies) exist and were successful but the goshawks did not respond to tapes or their responses were undetected. To evaluate these alternatives more thoroughly, we recommend a minimum of one more year of inventory be conducted during the 1994 field season on portions of the area covered in 1993. This is consistent with Kennedy and Stahlecker (1993) who recommend an area should be surveyed a minimum of two consecutive nesting seasons to minimize the number of unsuccessful territories missed during a survey. The focus of the 
1994 inventory should be restricted to areas of suitable goshawk nesting habitat.

\section{MANAGEMENT IMPLICATIONS}

Two goshawk nests have been found near the LANL inventory area on SFNF (Map 3). Both territories were occupied in 1993 but only one territory produced young (Kennedy, unpubl. data). Portions of the goshawk home ranges for these territories cross LANL boundaries (Map 3). These areas are potential foraging areas for the nesting goshawks.

The USDA, Forest Service has published recommendations for management of the goshawk in the southwestern United States (Reynolds et al. 1992). According to Reynolds et al. (1992), there are two possible reasons for goshawk population limits: 1) prey availability, and 2) nesting habitat availability. Prey availability can be enhanced by managing for the habitat of important prey species which include squirrels, chipmunks, woodpeckers, jays, and rabbits. These prey species require a variety of habitat characteristics. According to Reynolds et al. (1992) abundant populations of the dominant prey species in the goshawk diet will be present if these characteristics - including snags, downed logs, woody debris, large trees, herbaceous and shrubby underbrush, and a mixture of various forest vegetative structural stages (VSS) ${ }^{a}$ - are managed in goshawk home ranges. These guidelines should be implemented

\footnotetext{
a Vegetative Structural Stage is a description of forests based on the diameter distribution of the majority of trees in a stand. The diameter range and description for the vegetative structural stages are as follows: VSS $1=0-1$ in. DBH (Grass, Forb, Shrub); VSS $2=1-5$ in. DBH (Seedling/Sapling); VSS $3=5-12$ in. DBH (Young Forest); VSS $4=12-18$ in. DBH (Mid-Age Forest); VSS $5-18-24$ in. DBH (Mature Forest); VSS $6=24+$ in. DBH (Old Forest). DBH $=$ Diameter at Breast Height (4.5 ft.)
} 
on LANL to enhance goshawk habitat. The management guidelines are summarized below.

The goshawk nesting habitat which includes the nest area, the post-fledgling family area (PFA) and foraging areas can be enhanced by certain management techniques. Reynolds et al. (1992) recommend a synthesis of habitats within goshawk home ranges that contain important prey species requirements and other goshawk nesting habitat requirements. Since goshawks are found primarily in ponderosa pine, mixed-species, and spruce-fir forest types and their prey items do not occur in all of the forest types, mangement guidelines for each of the forest types were analyzed separately.

The nest areas are occupied by breeding adults and are the center of nesting activity. They are characterized by stands of mature and old trees and dense forest canopies (VSS 5 and 6). Three suitable nest areas and three alternate nest areas should be maintained within each home range. Each nest area should be 13.4 ha in size (Table 3).

A post-fledgling family area (PFA) surrounds the nest area and is used by the goshawk family after the young have fledged and while they are still dependent on their parents for food (up to two months) (Reynolds et al. 1992). The PFA is important to the fledglings for hiding cover and for the development of their hunting skills (Reynolds et al. 1992). PFAs range from 121 to 243 ha and average 168 ha (Kennedy 1990) while the guidelines suggest managing for a PFA of 187.5 ha (Reynolds et âl. 1\$92). The attributes of the PFA contain a variety of forest conditions (Table 3 ) interspersed with small openings. Snags, downed logs, and woody debris are important features of the PFA because they 
provide foraging habitat and cover for prey species used be juveniles during the fledgling-dependency period.

Foraging areas comprise the largest component of a territory and are estimated to average 2,411 ha. Goshawks forage in a variety of habitats and not much is known about how goshawks use foraging areas (Reynolds ot al. 1992). However Reynolds et al. (1992) surmise that goshawks use a variety of forest types of different structural stages for hunting. Important components of foraging areas include snags, downed logs, woody debris, openings, large trees, herbaceous and shrubby understories, and interspersion of forest age classes (Reynolds et al. 1992). These are important habitat characteristics of their dominant prey species. A more open canopy cover is preferred than the PFA because the assumption is that goshawks need a more open forest for greater maneuverablity to hunt (Reynolds et al. 1992) (Table 3).

The guidelines (Reynolds et al. 1992) have the following recommendations for managing goshawk foraging areas (Table 4). Forest regeneration is required every 20-30 years in small areas to maintain the desired canopy cover. Openings of $\leq 0.8$ ha are required for regeneration. If openings are $\geq 0.2$ ha then large, mature reserve trees should be left to regenerate the openings; openings $\leq 0.2$ ha will be regenerated by surrounding trees. Planting of ponderosa pine as well as encouraging aspen and oak regeneration in ponderosa pine and mixed species forests will improve goshawk habitat. Prescribed fire is the suggested technique for maintaining adequate woody debris Understory thinning with non-uniform spacing and prescribed burning is preferred for maintaining desired forest structure and will develop groups of 
trees with interlocking crowns. Road densities should be minimized. Forage utilization should be $\leq 20 \%$ to maintain grass, forb, and shrub layers.

The foraging areas of two known goshawk nesting territories overlap on LANL land (Map 3). The foraging area of a goshawk territory in Pajarito canyon overlaps LANL by 100.8 ha ( $4.2 \%$ of the total foraging area). The foraging area of a goshawk territory in Water Canyon overlaps LANL by 172.8 ha $(7.2 \%$ of the total foraging area). Both of these territories are found on the Española Ranger District of SFNF. The management guidelines (Reynolds et al 1992) should be implemented on these foraging areas within LANL.

By managing for goshawks in the southwest additional benefits occur including higher soil productivity, reduced risk of catastrophic fires, increased woody debris, large diameter snags, and downed logs are additional gains. In addition, suitable habitat will be provided for a diversity of mammals and birds that are prey species of the goshawk and other predators.

\section{ACKNOWLEDGMENTS}

We would like to thank Delia F. Raymer, Debbie Risberg, and Mary Salisbury for providing escort assistance into restricted areas, preparing the necessary daily paperwork, and accommodating our unpredictable time schedule. Their assistance was of great value. Teralene Foxx and Kathryn Bennet provided logistical support, and coordination and communication among the varying departments that allowed the field season to run smoothly. Finally, we would like to thank our families for their love and support. 


\section{LITERATURE CITED}

Fuller, M. A., and J. A. Mosher. 1981. Methods of detecting and counting raptors: a review. Pages 235-246 in B. G. Pendleton, B. A. Millsap, K. W.

Cline, and D. M. Bird, eds. Raptor management techniques manual. Natl. Wildl. Fed. Sci. Tech. Ser. No. 10.

Kennedy, P. L. 1990. Home ranges of northern gohsawks nesting in northcentral New Mexico. Page 259 in P. R. Krausman and N. S. Smith, eds. Managing wilditi in the southwest. Ariz. Chap. the Wild Soc., Phoenix, Ariz.

Kennedy, P. L. 1991. Reproductive strategies of northern goshawks and Cooper's hawks in north-central New Mexico. Ph.D.. Diss, Utah State University, Logan, UT.

Kennedy, P. L and D.W. Stahlecker. 1993. Responsiveness of nesting northern goshawks to taped broadcasts of three conspecific calls. J. Wild Manage. 57:249-257.

Reynolds, R. T. 1982. North American accipiter hawks. pg 288-289 in D. E. Davis (ed.) Handbook of census methods for terrestrial vertebrates. CRC Press, Inc. Boca Raton, FI.

Reynolds, R. T., R.T. Graham, M.H. Reiser, R.L. Basset, P.L. Kennedy, D.A. Boyce, Jr., G. Goodwin, R. Smith and E.L. Fisher (Northern Goshawk Scientific Committee, USDA Forest Service, Southwestern Region). 1992. Management recommendations for the northern goshawk in the southwestern United States. USDA For. Serv. Rocky Mountain For. Range Exp. Sta Gen. Tech. Rep. RM-217. 
Rosenfield, R. N., J. Bielefeldt, and R. K. Anderson. 1988. Effectiveness of broadcast calls for detecting breeding Cooper's hawks. Wildl. Soc. Bull. 16:210-212. 
Figure 1. Inventory data sheet used during accipiter inventory on Los Alamos National Laboratory in 1993.

INVENTORY DATA SHEET

Page - of -

Date:

Observer:

Time Start:

End:

Survey Area

Quad Name

Starting Point: T

$\mathrm{R}$

$\mathrm{Sec}$

$1 /+\ldots-1 / 4$

Drainage Station Species Sexldge Response Time Comments

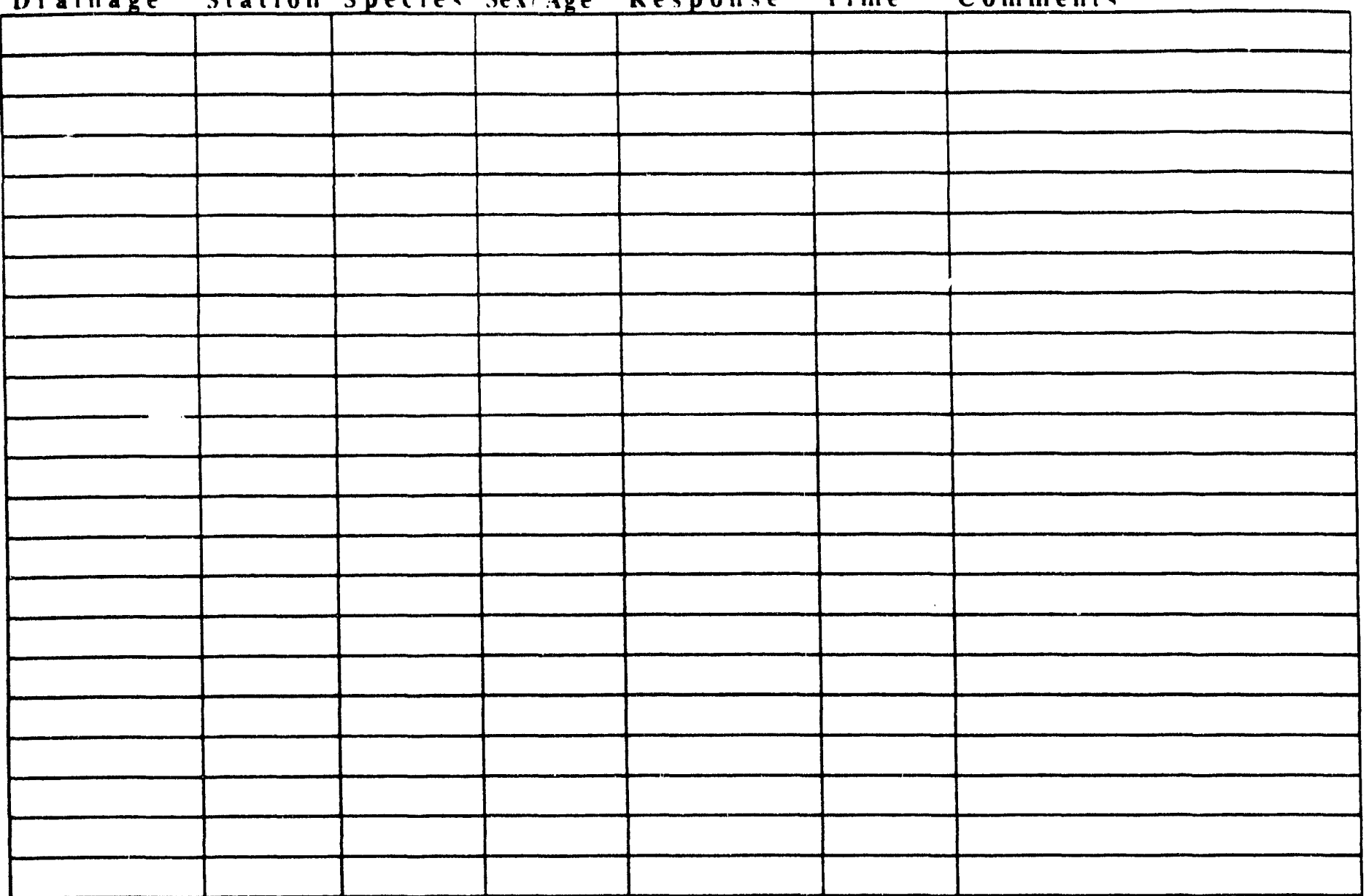

Species:

NOGO-NorthernGoshawk

COHA-Cooper's Hawk

SSHA-Sharp-Shinned

UNAC-Unknown Accipiter

STJA-Steller's Jay

RTHA-Red Tailed Hawk

UNRA-Unknown Raptor
Sex/Age:

F-Female

M-Male

A-Adult

Y-Young

U-Unknown
Response:

0 -None

1-Vocal:
a) wail
b) kekk
c) beg

d) other/unknown

2-Visual (Silent)

3-Vocal then Visual

4-Visual then Vocal

5-Mimic

6-Other 
Tabie 1. Summary of the 1993 northern goshawk inventory effort on Los Alamos National Laboratory.

\begin{tabular}{|l|l|l|l|l|}
\hline \multirow{2}{*}{ Date } & \multicolumn{3}{c|}{ Stant } & \multicolumn{2}{c|}{ Time (Military) } & \multirow{2}{*}{ Total Stations } \\
\cline { 2 - 5 } $5 / 12 / 93$ & $13: 58$ & $18: 00$ & 4.0 & 33 \\
\hline $5 / 13 / 93$ & $09: 27$ & $17: 03$ & 7.6 & 39 \\
\hline $5 / 19 / 93$ & $08: 40$ & $16: 45$ & 8.1 & 54 \\
\hline $5 / 20 / 93$ & $09: 49$ & $12: 30$ & 2.7 & 17 \\
\hline $5 / 21 / 93$ & $08: 20$ & $15: 24$ & 7.1 & 63 \\
\hline $6 / 4 / 93$ & $07: 58$ & $13: 16$ & 5.3 & 38 \\
\hline $6 / 11 / 93$ & $08: 44$ & $15: 10$ & 6.4 & 34 \\
\hline $7 / 30 / 93^{2}$ & $08: 05$ & $10: 47$ & 2.7 & 26 \\
\hline
\end{tabular}

\begin{tabular}{|l|l|l|l|l|}
\hline Total & & & 43.9 Hours & 304 Stations \\
\hline Average & & & & 6.9 StahHr \\
\hline
\end{tabular}

a Inventory on this area repeats coverage of an inventory area conducted on May 21, 1993 because of a sighting of an unknown (either Cooper's hawk of goshawk) immature accipiter. 
Table 2. Raptor responses and observations detected during the northern goshawk inventory on Los Alamos National Laboratory land in 1993.

\begin{tabular}{|c|c|c|c|}
\hline Date & Speciesa & Area & Comments \\
\hline 12-May & RTHA & Two-Mile Canyon & $\begin{array}{l}\text { First mimics were heard, then aggressive } \\
\text { response. }\end{array}$ \\
\hline 13-May & RTHA & Two-Mile Canyon & $\begin{array}{l}\text { RTHA nest found with } 3 \text { nestlings. Nest is in a } \\
\text { white fir at bottom of drainage. }\end{array}$ \\
\hline 13-May & UNRA & Two-Mile Canyon & $\begin{array}{l}\text { An owl roost found with pellets under it. } \\
\text { Pellets seemed too small to be great-horned } \\
\text { owl pellets. Spotted owl pellets? They were } \\
\text { collected to be analyzed later by LANL. }\end{array}$ \\
\hline 13-May & $\infty+4$ & Two-Mile Canyon & $\begin{array}{l}\text { Flew to the west. Probably not responding to } \\
\text { tape. }\end{array}$ \\
\hline 19.May & UNRA (?) & Pajarito Canyon & $\begin{array}{l}\text { An empty nest was found about Cooper's hawk } \\
\text { size. }\end{array}$ \\
\hline 21-May & UNAC & Cañon de Valle & $\begin{array}{l}\text { An immature Cooper's hawk or a goshawk } \\
\text { responded to a broadcast. The bird circled \& } \\
\text { then flew out of area. }\end{array}$ \\
\hline $21 \cdot$ May & GHOW & Cañon de Valle & $\begin{array}{l}\text { A great horned owl responded to the broadcast } \\
\text { and then flew down hill. }\end{array}$ \\
\hline $4-J u n$ & GHOW (?) & Water Canyon & $\begin{array}{l}\text { A large gray bird fiew from a roost beneath us } \\
\text { toward main canyon. Probably a great horned } \\
\text { owl. Found an owl roost (great horned owl?) } \\
\text { with } 3+\text { pellets. Also found a great horned owl } \\
\text { feather. }\end{array}$ \\
\hline $4 \cdot J$ un & RTHA & Water Canyon & $\begin{array}{l}\text { Flew over head. Primary on left wing is } \\
\text { broken and falling off. }\end{array}$ \\
\hline $11 . J$ un & RTHA & Cañon de Valle & Soaring off in the distance. \\
\hline $11-J$ un & GHOW & Pajarito & $\begin{array}{l}\text { Found a great-horned owl nest. Pellets } \\
\text { everywhere but no mute. Nest is in drainage. }\end{array}$ \\
\hline $30-541$ & RTHA & Canion de Valle & Vocalizations. \\
\hline $30 . J 41$ & GHOW (?) & Cañon de Valle & Found a tresh moist cast, probably GHOW. \\
\hline
\end{tabular}

a COHA = Cooper's Hawk; GHOW = Great-horned owi; RTHA = Red-tailed Hawk; UNAC = Unknown Accipiter; UNRA = Unknown Raptor. 
Table 3. Summary of desired forest conditions in three forest types for sustaining northern goshawks in the southwestern United States. ${ }^{a}$

\begin{tabular}{|c|c|c|c|c|c|c|c|}
\hline \multirow[b]{3}{*}{ Attributo } & \multicolumn{7}{|c|}{ Home Range Components } \\
\hline & & \multicolumn{3}{|c|}{ Post Family-flodgling Area } & \multicolumn{3}{|c|}{ Foraging Area } \\
\hline & $\begin{array}{l}\text { Suitable } \\
\text { Nest Area }\end{array}$ & $\begin{array}{l}\text { Ponderosa } \\
\text { Pine }\end{array}$ & $\begin{array}{l}\text { Mixed- } \\
\text { Species }\end{array}$ & Spruce-Fir & $\begin{array}{l}\text { Ponderosa } \\
\text { Pine }\end{array}$ & $\begin{array}{l}\text { Mixed } \\
\text { Species }\end{array}$ & Spruce-Fir \\
\hline \multicolumn{8}{|l|}{ VSS DIstribution \%c } \\
\hline VSS 1 grass/iorb/shrub & 0 & 10 & 10 & 10 & 10 & 10 & 10 \\
\hline VSS 2 seodling-saping & 0 & 10 & 10 & 10 & 10 & 10 & 10 \\
\hline VSS 3 young forest & 0 & 20 & 20 & 20 & 20 & 20 & 20 \\
\hline VSS 4 mid-aged forest & 0 & 20 & 20 & 20 & 20 & 20 & 20 \\
\hline VSS 5 mature forest & \multirow[t]{2}{*}{100} & 20 & 20 & 20 & 20 & 20 & 20 \\
\hline VSS 6 old growth & & 20 & 20 & 20 & 20 & 20 & 20 \\
\hline \multicolumn{8}{|l|}{ Canopy Cover \% } \\
\hline VSS 4 & NAd & $\begin{array}{l}1 / 360+\theta \\
1 / 340+\end{array}$ & $60+$ & $60+$ & $40+$ & $\begin{array}{l}1 / 360+\theta \\
2 / 340+\end{array}$ & $\begin{array}{l}1 / 360+\theta \\
2 / 340+\end{array}$ \\
\hline VSS 5 & $50+$ & $50+$ & $60+$ & $70 t$ & $40+$ & $50+$ & $60+$ \\
\hline VSS 6 & $50+$ & $50+$ & $60 t$ & $70+$ & $40+$ & $60 t$ & $60+$ \\
\hline Years to reach VSS 6 & $200-300$ & 200.250 & $200-300$ & $200-300$ & $200-250$ & $200-300$ & 200300 \\
\hline \multicolumn{8}{|l|}{ Openings } \\
\hline W/ Reserve trees (AC) & 0 & 2 & 2 & 1 & 4 & 4 & 1 \\
\hline WO/Reserve trees (AC) & 0 & $1 / 2$ & $1 / 3$ & $1 / 3$ & $1 / 2$ & $1 / 3$ & $1 / 3$ \\
\hline Width $(t)$ & NA & 200 & 150 & 125 & 200 & 200 & 125 \\
\hline \multicolumn{8}{|l|}{ Reserve Trees } \\
\hline Number (per group) & NA & $3-5$ & 6 & 6 & 3.5 & 6 & 6 \\
\hline Number of Groups & $A^{9}$ & 1 & 1 & 2 & 1 & 1 & 2 \\
\hline Snags (AC) & $N A^{h}$ & 2 & 3 & 3 & 2 & 3 & 3 \\
\hline Downed logs (AC) & Na & 3 & 5 & 5 & 3 & 5 & 5 \\
\hline Woody debris (Tons/AC) & NR & $5-7$ & 10.15 & $10-15$ & 5.7 & 10.15 & 10.15 \\
\hline
\end{tabular}

a Sounce of Table: Reynolds et al 1992.

- Suitable nest area (capable of having nesting goshawks) attributes apply to all forest types.

c VSS: Vegetative structural stages, a description of forests based on the location of the majority of the trees in the diameter distribution of a stand. For example, if the majority of the stems of a stand (based on basal area) were located in the 12-18 inch diameter class, the stand would be classified as a VSS 4. General cliameter limits are: VSS 1=0-1" DBH, VSS $2=1-5^{\prime \prime} \mathrm{DBH}$, VSS 3-5-12" DBH, VSS 4=12-18" DBH, VSS 5=18-24" DBH, VSS 6=24"+ DBH. DBH=Diameter at Breast Height (4.5 ft.).

d NA: Not applicable.

- Proportion of home range component.

'Reserve trees: Standing trees left after harvesting that will be allowed to become snags and downed logs.

I A: Applicable, clumpiness or groups of large trees is also desirable.

$n$ NR: Not Required, but presence of these features are not detrimental. 
Table 4. Summary of management recommendations for producing and maintaining northem goshawk habitat in the southwestern United States. ${ }^{a}$

\begin{tabular}{|c|l|l|l|}
\hline \multirow{2}{*}{ Attribute } & \multicolumn{3}{|c|}{ Home Range Component } \\
\cline { 2 - 5 } & \multicolumn{1}{|c|}{ Nest Areab } & \multicolumn{1}{c|}{ PFA } & \multicolumn{1}{c|}{ Foraging Area } \\
\hline Number & 6 & 1 & 1 \\
\hline Suitable & 3 & NA & NA \\
\hline Replacement & 3 & NA & NA \\
\hline Size (AC) & 30 & 420 & 5.400 \\
\hline Management Season & Oct-Apr & Oct-Apr & Year-Long \\
\hline Regeneration & & & \\
\hline Conifer & None & Yes & Yes \\
\hline Aspen \& Oakc & None & Yes & Yes \\
\hline Planting & None & Yes & Yes \\
\hline Thinning from Below & Non-Uniform Spacing & Non-Uniform Spacing & Non-Uniform Spacing \\
\hline Roads & & & \\
\hline System & Minimum Density & Minimum Density & Minimum Spacing \\
\hline Skid & Permenant & Permenant & Permanent \\
\hline Forage Utilization (\%) & 20 & 20 & 20 \\
\hline Woody Debris Treatment & & \multicolumn{2}{|c|}{ In Order of Preference } \\
\hline Prescribed Burning & 1 & 1 & 1 \\
\hline Lopping \& Scattering & 2 & 2 & 2 \\
\hline Hand Piling & 3 & 3 & 3 \\
\hline Machine Grapple Piling & None & 3 & 4 \\
\hline Dozer & None & 4 & 3 \\
\hline
\end{tabular}

a Table Source: Reynolds 1992.

b Nest areas may be made up of one or more forest types.

c Oak not applicable in the spruce-fir forest type.

d Not applicable in spruce-fir forest type. 
Map 1. Northern goshawk inventory routes on Los Alamos National Laboratory, Los Alamos, NM in 1993.
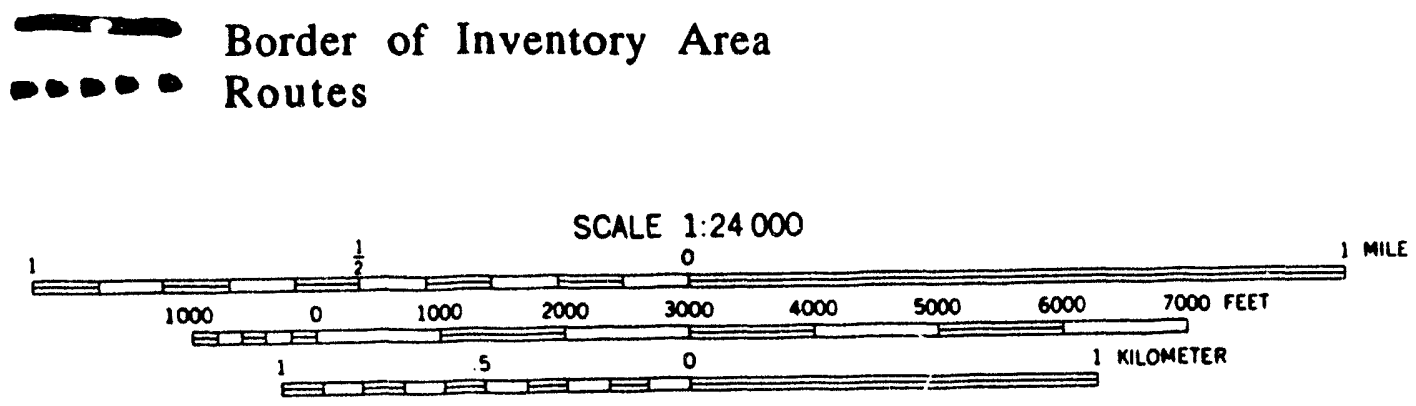

CONTOUR INTERVAL 20 FEET

NATIONAL GEODETIC VERTICAL DATUM OF 1929 





Map 2. Raptor sightings during 1993 northern goshawk inventory on Los Alamos National Laboratory.

Border of Inventory Area

$\mathbf{N}=$ Nest $\quad$ COHA $=$ Cooper's Hawk

$\mathrm{V}=$ Visual

GHOW $=$ Great Horned Owl

$\mathrm{R}=$ Roost

RTHA = Red-tailed Hawk

UNAC $=$ Unidentified Accipiter

SCALE $1: 24000$

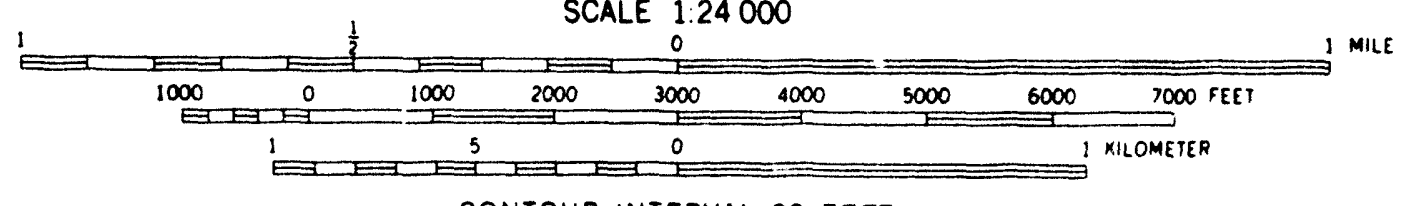

CONTOUR INTERVAL 20 FEET

NATIONAL GEODETIC VERTICAL DATUM OF 1929 


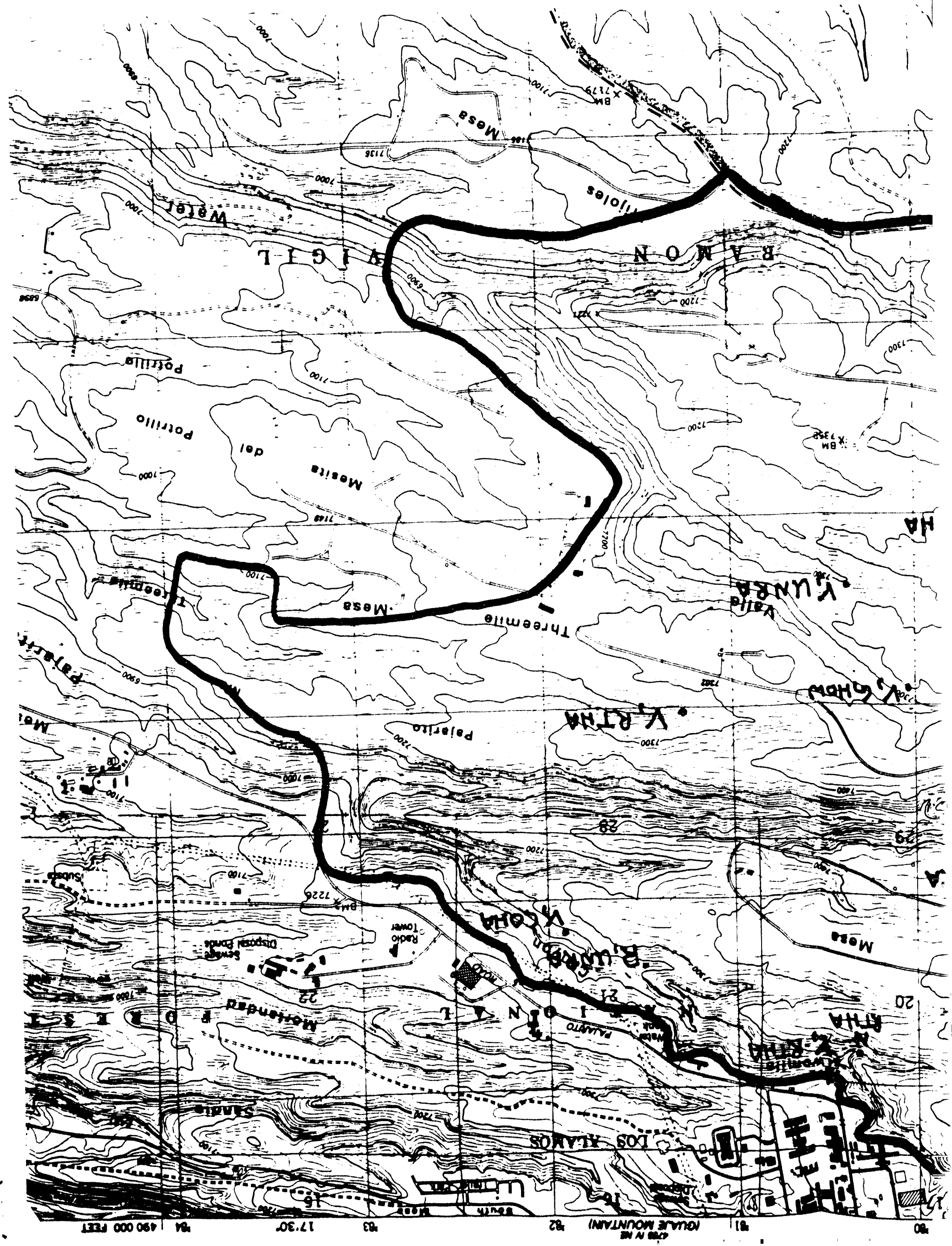




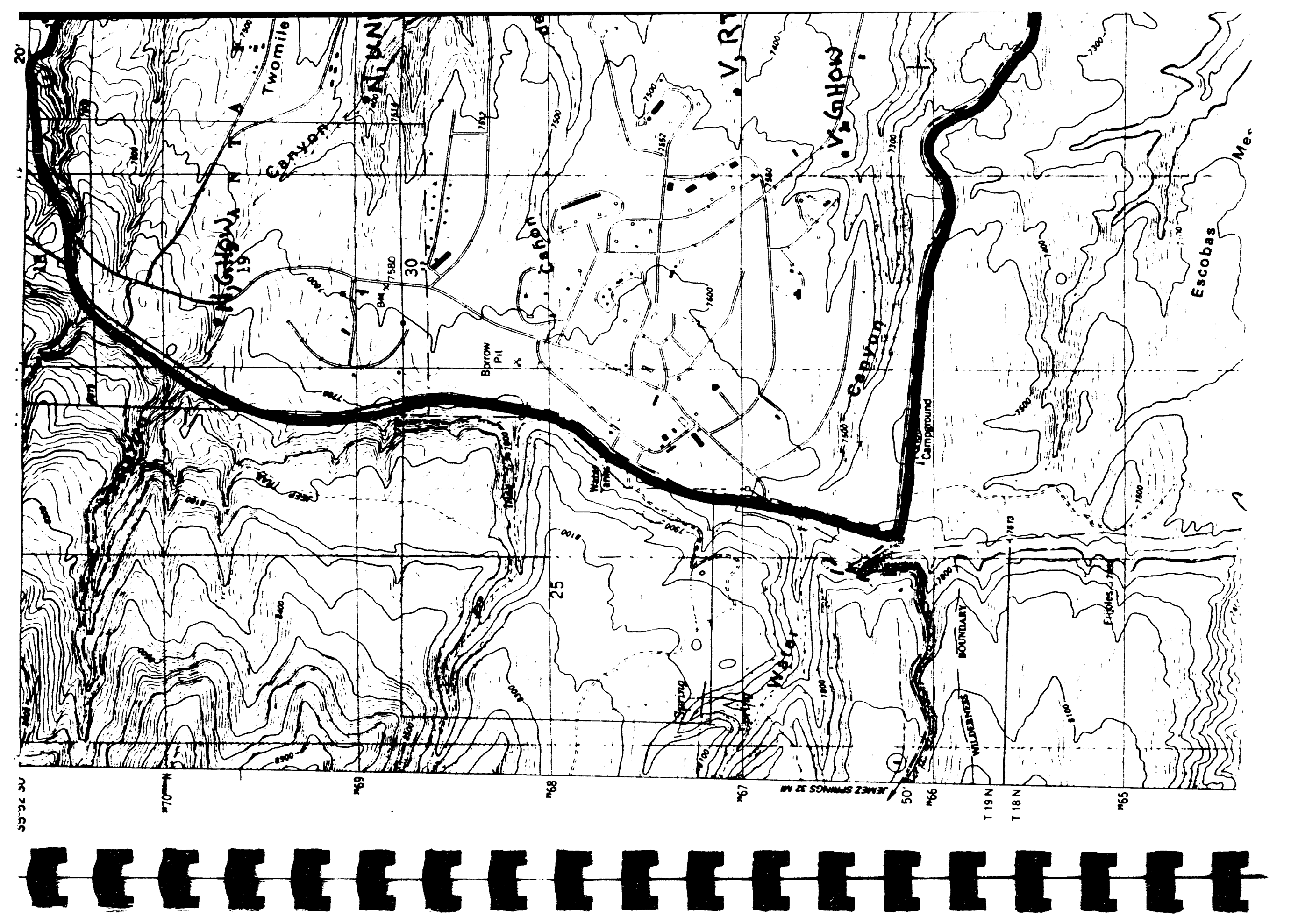


$m 70^{\infty}$

Map 3. Post-fledgling Family Area and Foraging Area boundaries of northern goshawks on Santa Fe National Forest that overlap Los Alamos National Laboratory.

$\longrightarrow$ LANL Border

Foraging Area Boundary

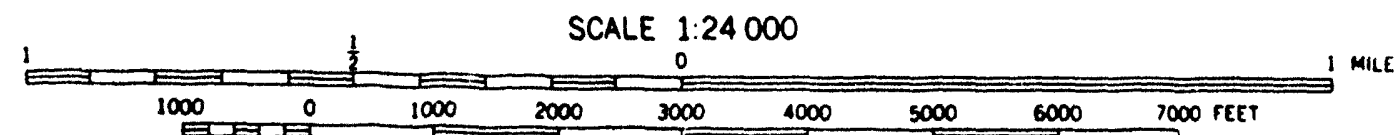

$m$

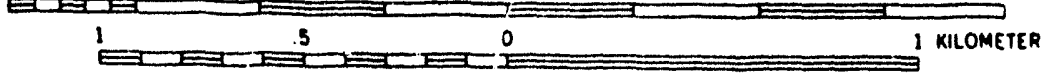

CONTOUR INTERVAL 20 FEET

NATIONAL GEODETIC VERTICAL OATUM OF 1929

n6

T19

T $18 \mathrm{~A}$ 


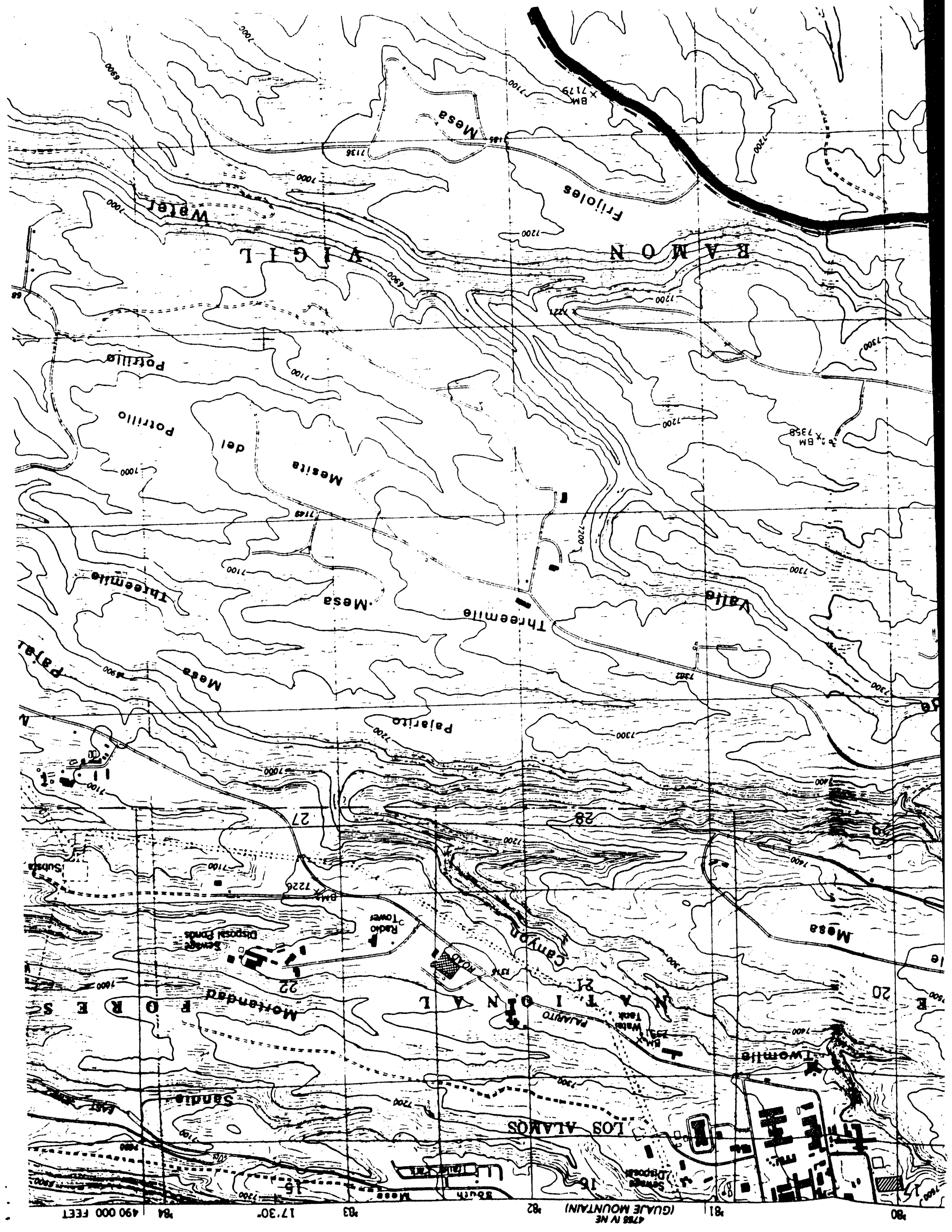




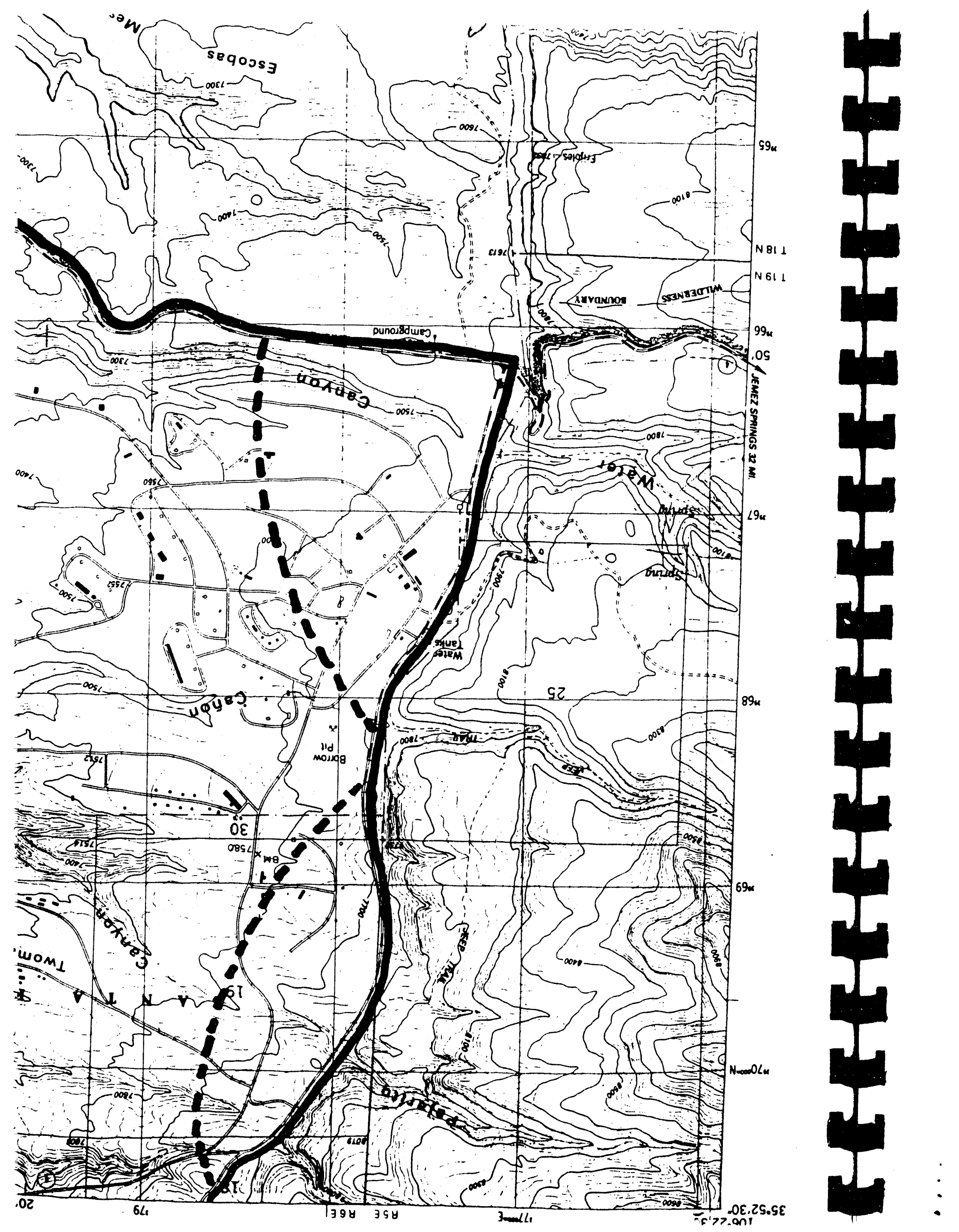



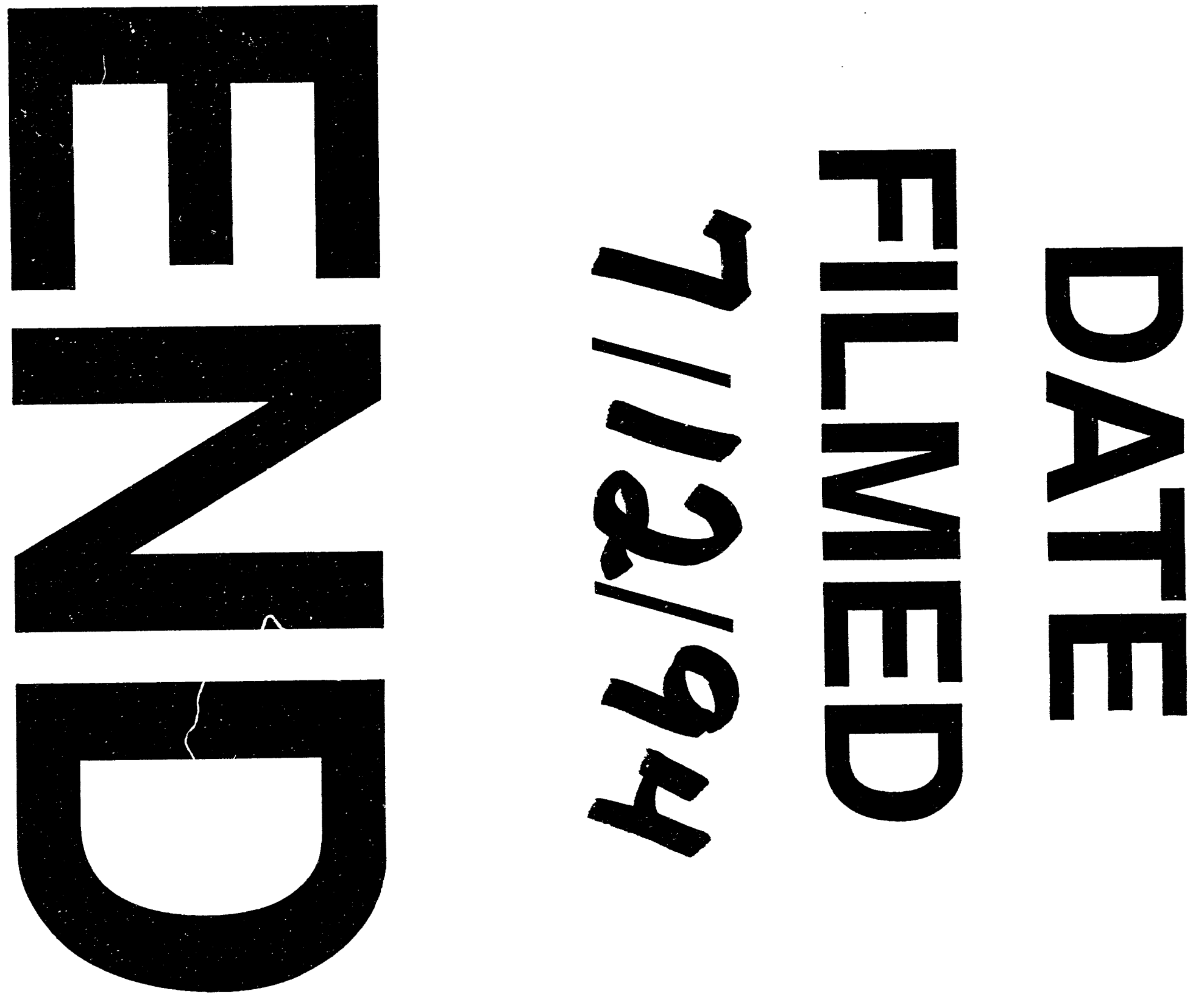

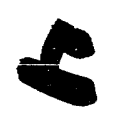




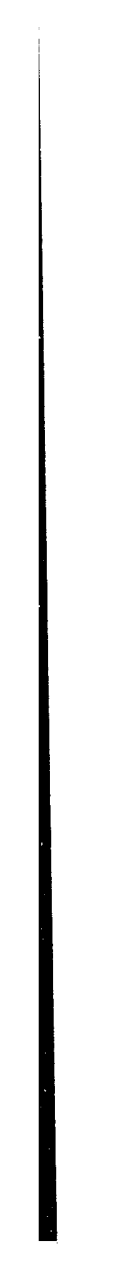

